\title{
La visión del harén en la prosa de las viajeras europeas: entre la seducción y el rechazo. El caso especial de Aurora Bertrana (1892-1974)
}

\author{
Isabel MARCILLAS PIQUER \\ Departament de Filologia Catalana \\ Universitat d'Alacant \\ isabel.marcillas@ua.es
}

\begin{abstract}
RESUMEN
A causa de los estereotipos difundidos por el orientalismo, los harenes se convirtieron en símbolo de la cultura oriental, sinónimo de sensualidad y de desenfreno sexual. Viajeras como Cristina Trivulzio di Belgiojoso, Olympe Audouard, Carla Serena, Ida Hahn o la catalana Aurora Bertrana, a través de sus libros de viajes, se erigieron en auténticas conocedoras de la vida en los harenes y nos aportaron, con sus textos, una visión de la mujer musulmana que se suscribe, contrapone o complementa la aportada por la mirada del hombre. Este artículo recupera las voces de viajeras europeas de nacionalidades diversas que se desplazaron a países culturalmente orientales, en un abanico temporal que oscila entre los años cuarenta del siglo XIX y la década del treinta del siglo XX, sin que ello sea un obstáculo para que presenten opiniones y testimonios paralelos.
\end{abstract}

Palabras clave: Aurora Bertrana, viaje, harenes, Orientalismo.

[Recibido, enero 2014; aprobado, enero 2015]

The vision of the harem in the prose of European travellers: between seduction and rejection. The case special of Aurora Bertrana (1892-1974)

\begin{abstract}
Due to the stereotypes spread by Orientalism, harems turned into a symbol of Traditional Oriental Culture, synonymous of sensuality and sexual debauchery. Travelers as Cristina Trivulzio di Belgiojoso, Olympe Audouard, Carla Serena, Ida Hahn or the Catalan writer Aurora Bertrana became authentic experts about life in harems and provided us, through their travel books, with a view of Muslim women which subscribes, contrasts or complements that provided by men's gaze. This article recovers the voices of women travellers who belong to different European nationalities. They travelled to culturally Oriental countries, in a temporal range from the 1840 s to the 1930 s, without it being an obstacle to submit reviews and parallel evidence.
\end{abstract}

Keywords: Aurora Bertrana, travel, harems, Orientalism. 


\section{Introducción}

Todavía hoy, el harén constituye para los occidentales el mito oriental por excelencia. Sinónimo de orgía sexual, la poligamia del señor del harén y la libidinosidad de las mujeres que lo habitaban epitomizan la barbarie oriental y metaforizan toda una cultura que ha nutrido durante siglos la imaginación occidental.

La conquista de Constantinopla por los otomanos el 1453 supuso un gran choque cultural por medio del cual los europeos tomaron consciencia de la fuerza de la fe que animaba a los conquistadores vecinos. Las primeras diferencias que se establecieron con la alteridad fueron, pues, de orden religioso. Aunque los europeos declaraban su horror frente a una religión mal conocida que parecía aceptar toda clase de vicios de índole sexual, la atracción por el exotismo que ésta escondía se hacía patente en los textos de los viajeros que, a partir del siglo XVII, resultaron cada vez más numerosos. La producción literaria surgida a raíz de estas estancias en tierras extranjeras crecía frente al interés de un público que pedía más relatos, estimulado por el deseo de conocimiento de una cultura que le fascinaba en tanto que la propia moral le obligaba a rechazarla.

Fue Antoine Galland, secretario del embajador del rey portugués en Turquía, quien, entre el 1704 y el 1717, realizó la traducción de una serie de cuentos que formaban parte de Las mil y una noches. Estas historias representaban un legado de la literatura folclórica oral proveniente de la India, Persia, Irak, Siria y Egipto, motivo por el cual no se trataba de textos cerrados, sino que los hakawatieh - una especie de trovadores orientales- los reformulaban constantemente, aumentado su contenido o adaptándolos a los gustos del público. Las versiones resultantes de estas modificaciones reflejan las singularidades culturales de cada lugar de origen, aunque cabe destacar que no eran considerados como literatura culta, sino como historias destinadas al entretenimiento de un público poco cultivado (Kabbani 1986: 23).

Con estos cuentos Antoine Galland no fue mucho más cuidadoso que los trovadores orientales y, más que traductor, actuó como adaptador a los gustos del público francés. El mismo Galland confiesa no haberse ceñido justamente a los textos, atendiendo al hecho de que no hubieran gustado a los lectores europeos; de manera que los trasladó al francés tan bien como le fue posible, sin hacer una traducción del todo respetuosa (Kabbani 1986: 27).

El 1859, las historias que componían Las mil y una noches se traducían también al inglés por Stanley Lane Poole y sufrían una nueva transformación, esta vez adecuada al público de la sociedad vitoriana inglesa. Así, estos cuentos habían pasado a hacer referencia a un Oriente imaginario construido según los deseos de los occidentales. El interés de los europeos por Las mil y una noches se centraba, principalmente, en aquellas historias en las cuales se manifestaba la violencia considerada implícita en la cultura oriental. Una violencia, además, que desde el principio se había relacionado con la sexualidad, las restricciones y los castigos que a menudo eran impuestos a las mujeres que transgredían las normas del harén ${ }^{1}$.

\footnotetext{
${ }^{1}$ Para ampliar esta información vean Jean Chardin, Voyage de Monsieur le Chevalier Chardin en Perse et Autres Lieux de l'Orient, 2 vols. 1686, Amsterdam.
} 
Cuando Lady Mary Wortley Montagu viajó a Oriente el $1716^{2}$, los relatos de Las mil y una noches ya se habían confundido con el Oriente real y formaban parte del imaginario del cual la joven viajera británica tendría que constatar, a partir de la propia experiencia, la veracidad. Contrariamente a lo que se habría podido esperar, Montagu, considerada la primera europea que facilitó la descripción interior de un harén, no incidió en el encierro padecido por las mujeres orientales, ni en las posibles consecuencias psicológicas adversas por el hecho de haber compartido un mismo hombre, ni en los celos surgidos entre ellas, ni en los supuestos maltratos. En las cartas que Montagu dirigía a su hermana, la británica se refería al harén como un espacio de lujo donde las mujeres vivían de manera autárquica y podían desarrollar la personalidad al abrigo de la influencia masculina (Hodgson 2005: 113).

Estas declaraciones difieren de las ofrecidas por los viajeros y tenían mucha importancia ya que, contrariamente a lo que sucedía con las que proporcionaban los hombres, Lady Mary Wortley Montagu había sido testimonio en primera persona de aquello que relataba ${ }^{3}$.

Cabe destacar, pues, que los harenes, lugar sagrado dedicado a la vivienda de las mujeres, eran accesibles solamente a visitantes de este sexo, motivo por el cual las viajeras europeas que eran invitadas a conocer alguno se consideraban poseedoras de un saber especial, único y valioso, que debían reflejar, necesariamente, en sus libros de viajes para el conocimiento de la sociedad de la cual procedían. Pero la mirada que las viajeras europeas han transmitido del mundo oriental ha sido frecuentemente poco estudiada. Tenidas, en su momento, por mujeres estrafalarias que sin demasiados miramientos ocupaban parcelas destinadas al sexo masculino, tanto por lo que se refiere al viaje a territorios exóticos, como por lo concerniente a la posterior escritura de la experiencia vivida, la visión de las viajeras europeas de finales del XVII, del XIX e incluso de principios del siglo XX, ha sido menospreciada casi hasta la actualidad. Cristina Trivulzio di Belgiojoso, Olympe Audouard, Carla Serena, Susanne Voilquin o la misma Aurora Bertrana, son algunas de las mujeres que ofrecen con su prosa de viajes una mirada del mundo que complementa la tradicionalmente masculina, unas veces contradiciéndola, otras corroborándola. Ninguna de ellas puede sustraerse a la fascinación causada por el mundo de los harenes y, en consecuencia, todas ellas les dedican un espacio en sus crónicas viajeras.

\section{Objetivos}

Teniendo en cuenta el alcance socio literario del relato de los viajes a Oriente, este estudio se propone rescatar la voz de algunas viajeras europeas que aportaron su testimonio en cuanto a la vida de la mujer musulmana en los harenes, a través de la escritura de libros de viajes. Entre ellas, nos interesa particularmente la visión de la cronista catalana Aurora Bertrana (Girona, 1892 - Berga, 1974), que viajó sola a Marruecos el año 1935, con el

\footnotetext{
${ }^{2}$ Lady Mary Wortley Montagu acompañó a su marido que había sido enviado como embajador a Constantinopla entre el 1716 i el 1718.

${ }^{3}$ Otros viajeros no compartían la visión idealizada de los harenes que Lady Mary Wortley Montagu había transmitido. Así, por ejemplo, François de Tott, buen conocedor de la lengua y de las costumbres turcas, nombrado embajador de Crimea el 1767, en sus Mémoires du baron de Tott sur les Turcs et les Tartares, del 1784, acusa a la viajera inglesa de haber cedido a los gustos del público en sus descripciones. Para poder formular la acusación se basa en el testimonio de su mujer, que había conversado con la sultana de Asmar (Moussa 1995: 182).
} 
firme propósito de redactar unas crónicas que permitieran conocer al público catalán la vida de las mujeres musulmanas. De esta manera, el artículo que presentamos nos permite abordar un doble objetivo: en primer lugar, visualizar la voz de diversas viajeras europeas y así recuperar una visión femenina de la alteridad, a menudo menospreciada frente a la masculina; $y$, en segundo lugar, situar la palabra de la autora catalana entre los escritos de las mujeres que se consideraron avanzadas a su tiempo, principalmente, por poseer un carácter aventurero que las llevó a describir para sus coetáneos realidades culturales que nada tenían que ver con las propias. Como comprobaremos a lo largo de este estudio, las procedencias, años de nacimiento y destinos de las distintas viajeras, son diversos, atendiendo a las circunstancias personales y sociales de cada una de ellas, hecho que nos permite trazar un eje cronológico que asocia la individualidad de cada una de sus voces con un interés común: la descripción de la vida de las mujeres musulmanas.

\section{Testimonios de las viajeras europeas}

\subsection{Palabra de mujer vs. palabra de hombre}

Las palabras de Carla Serena ${ }^{4}$ remarcan la importancia del testimonio de las viajeras en cuanto a la información que facilitan entorno a los harenes. Serena afirma que el Oriente es para los occidentales un territorio de cuento sobre el cual pueden escribirse toda clase de historias con total impunidad y comenta con referencia a esto: "Fui invitada a pasar algunos días con ellas en los misteriosos harenes, descritos a menudo de una forma poco verídica por aquellos que no han entrado nunca y donde el acceso no es siempre fácil para una extranjera"5 (Serena 1881: 79). La viajera de origen belga destaca dos cosas en estas líneas. La primera es que las descripciones del harén propuestas por el género masculino no son fidedignas. Resulta imposible que lo sean teniendo en cuenta que no ofrecen una información de primera mano, a diferencia de las mujeres, quienes, a pesar de su extranjería, tienen posibilidades de acceso si saben realizar los contactos oportunos. Por otro lado, la viajera subraya la dificultad de la tarea y, de esta manera, reafirma las propias aptitudes como mujer, viajera y cronista.

Cristina Trivulzio ${ }^{6}$ destaca también esta circunstancia que redunda en la exclusividad del género femenino como portador de la verdad en lo que se refiere al conocimiento de los harenes, y afirma:

Es cierto que estaba mejor situada que la mayoría de los viajeros para conocer una parte importante de la sociedad musulmana - la parte doméstica, donde domina la mujer. El harén, este santuario maho-

\footnotetext{
${ }^{4}$ Carla Serena es el pseudónimo literario de Caroline Hartog Morgensthein; nació en Bélgica entre el 1820 i el 1822. Adquirió la nacionalidad italiana cuando se casó con Leone Serena. Tuvo cinco hijos y no fue hasta que cumplió los cincuenta años que empezó su tarea periodística y su afición por los viajes. Entre otros destinos, recorrió Turquía, Oriente Próximo y Persia, donde fue acusada de espionaje. Las condiciones de vida de las mujeres de los países que visitaba le interesaban particularmente. Las Lettres Helleniques son el resultado de su experiencia oriental; las escribió para la Syllogus, una asociación para la instrucción de las mujeres de la cual fue nombrada miembro honorífico. En este trabajo hacemos referencia a su libro Mon voyage: Souvenirs personnels. De la Baltique à la mer Caspienne. Une Européenne en Perse, del 1881.

${ }^{5}$ Las traducciones de todos los textos han sido realizadas por la autora de este trabajo.

${ }^{6}$ Cristina Trivulzio di Belgiojoso (1808-1871): viajera de nacionalidad italiana que vivió en diversas ciudades europeas y que pasó algunos años cerca de Ankara. Asie Mineure et Syrie, souvenirs de voyages (1858) es el volumen que hemos consultado para este estudio.
} 
metano, herméticamente cerrado a todos los hombres, me fue abierto. Podía entrar en él libremente, podía conversar con los seres misteriosos que el hombre francés no puede percibir más que velados, podía interrogar a algunas de estas almas que nunca se desahogan y provocarlas a hacer confidencias preciosas sobre todo un mundo desconocido de pasiones e infortunios. (Belgiojoso 1858: 2)

La viajera italiana redunda con sus palabras en el misterio que entraña el conocimiento de las mujeres musulmanas. Calificando el harén como santuario e incidiendo en las pasiones e infortunios que allí se viven, estimula el deseo en el occidental, capta al lector y le asegura la veracidad de su testimonio de mujer. Las viajeras se convertían así no sólo en exploradoras y observadoras de una nueva realidad, sino también en cronistas que debían a sus lectores la recreación de una cultura que, hasta ese momento, sólo había llegado a Occidente a través de la mirada masculina.

\subsection{El sentimiento de desencanto: realmente no son tan bellas}

Por otro lado, los testimonios de las mujeres no siempre coincidían con los propagados por la corriente orientalista vigente. Ida Hahn-Hahn, por ejemplo, desmitificaba la belleza y la sensualidad de la mujer oriental. A lo largo del viaje que realizó a Constantinopla entre 1843 y 1844, Hahn-Hahn tuvo la oportunidad de contemplar desde lejos a las mujeres del sultán que, habitualmente encerradas en el harén, salían a pasear. De esta experiencia, gracias a la cual dotaba de cuerpo y forma a las mujeres tradicionalmente resguardadas bajo el velo, afirma: "en realidad, cuando se las ve en libertad en la naturaleza, son un poco más fofas y pesadas. [...] ¡Qué manera de andar! ¡Qué piernas torcidas, y qué pies girados hacia adentro!" 7 . Se trata de observaciones que, sin lugar a dudas, ponen en entredicho la belleza y la sensualidad que, de forma casi pactada, se otorgaba a las mujeres orientales a través de los estereotipos difundidos por la literatura o la pintura.

Las afirmaciones de Maria L. Ratazzi ${ }^{8}$ y de la catalana Aurora Bertrana cuando recuerda la experiencia vivida en Marruecos en sus Memòries fins al 1935 (1973) ${ }^{9}$, tienen en común el sentimiento de desencanto al topar con una realidad que no se ajustaba al imaginario preestablecido por los occidentales y con el cual las dos viajaban como equipaje. Veamos los asombrosos paralelismos existentes entre el texto de la autora irlandesa y el de la periodista catalana, escrito casi cuatro décadas después:

¡Un harén! ¿No es verdad que esta palabra evoca enseguida entre nosotros fastuosas escenas de las Mil y una noches, danzas lascivas de hurís, de odaliscas y de bailarinas vestidas con telas de gasa con hilos de oro y plata, grupos de cadines — las favoritas del maestro- cómodamente sentadas sobre co-

\footnotetext{
${ }^{7}$ Citado a través de Sarga Moussa (1995: 187). Ida Hahn-Hahn escribió Orientalische Briefe en tres volúmenes, que fueron publicados en Berlín por la editorial Duncker, en el año 1844. Se trata de una serie de cartas escritas por la autora a lo largo de su viaje; a pesar de que no fueros traducidas francés, eran conocidas por ciertos viajeros franceses.

${ }^{8}$ Maria Leticia Rattazzi (1830-1902), nieta de Luciano Bonaparte, nació en Waterford (Irlanda). Casada tres veces, la conocemos con el apellido de su segundo marido. Era asidua a las tertulias literarias que promovía su madre, frecuentadas por Víctor Hugo y Alejandro Dumas, entre otros. Posteriormente tuvo su propia tertulia. Viajó a Turquía el año 1897.

${ }^{9}$ Como resultado de la experiencia viajera a Marruecos, Aurora Bertrana publicó una serie de crónicas que, posteriormente, reelaboró para su libro El Marroc sensual i fanàtic, Barcelona, Edicions Mediterrània, 1936. En las memorias que citamos, la autora reproduce casi todo el contenido de su libro y añade, además, algún que otro comentario como el que aquí hemos reproducido.
} 
jines bordados entres vapores de incienso? Y bien, querido, nada de todo esto existe en la vida real, y ciertamente uno se figura en Europa [...] que los países orientales son todavía países encantados, con voluptuosos peligros. (Rattazzi 1897: 75-77)

\begin{abstract}
¡Un harén! Ya he visto dos o tres. Sé que es el lugar donde los moros encierran a las hembras. A veces se encuentra la madre, la mujer, las hermanas, las hijas y las concubinas, y también las sirvientas. No es aquel lugar lleno de misterio que despierta la morbosa curiosidad de los europeos. Es la casa, la familia, el hogar más o menos confortable donde el hombre acomodado cuida a un montón de mujeres inútiles, les asegura comida y techo sin pedirles gran cosa. En resumen, no difiere, no difería demasiado ahora hace treinta años, de muchos hogares peninsulares todavía patriarcales, donde, excepto la concubina - a ésta el burgués peninsular la mantenía a parte-, vivían tres generaciones de hembras que no siempre permanecían encerradas con llave, pero que sólo salían para ir a misa y a las cuarenta horas. (Bertrana 1973: 818)
\end{abstract}

La decepción resulta evidente, como lo es también el deseo de dejar constancia de la realidad; una realidad prosaica, mediocre, en la que las mujeres, lejos de destacar por la belleza, se distinguen por su carácter sumiso y apático. Observemos no obstante que la viajera catalana, cuando décadas después redacta sus memorias e incide en su viaje a Marruecos, destaca con valentía la semejanza entre la sociedad oriental y la de la España de su juventud: ambas, salvando las distancias, eminentemente patriarcales con el beneplácito de las mismas mujeres.

\title{
3.3. Del exotismo a la animalización
}

Les Mystères de l'Égypte dévoilés, Le Mystère des sérails et des harems turcs y L'Orient et ses peuplades, son los textos resultantes de la experiencia viajera de Olympe Audouard ${ }^{10}$, publicados entre 1864 y 1865 . También Olympe Audouard quiere mostrar al mundo occidental aquello que ocurre a las mujeres en el interior del harén, en este caso, haciendo alusión en sus narraciones a los dos sentimientos contrapuestos que le produce este espacio cerrado. Así, por un lado, el harén se convierte en un lugar en que la mujer disfruta de libertad atendiendo al hecho de que escapa de la vigilancia del hombre —en este sentido, se acerca a la visión de la pionera, Lady Montagu. Pero, por otra parte, la escritora deja que sus textos muestren al mismo tiempo una barbarie inspirada en los cuentos de Las mil y una noches, en que las mujeres que se han atrevido a engañar al marido mueren decapitadas o, incluso, troceadas. Aún corriendo el riesgo de caer en los estereotipos preponderantes, o con la intención de hacer hincapié en ellos, se trata de textos a caballo entre la fascinación, desbocada hacia el exotismo cultural de Oriente, y la denuncia de las atrocidades que sufre el género femenino.

\footnotetext{
${ }^{10}$ Olympe Audouard (1832-1890) creció en Marsella bajo el nombre de Félicité-Olympe de Jouval; en 1850 se casó con un abogado Henri Alexis Audouard, de quien se separó ocho años después; a pesar de eso, no pudo conseguir el divorcio hasta el año 1885, después de ser aprobada la Loi Naquet, la ley francesa del divorcio. Audouard fue una feminista que luchó por la igualdad de las mujeres, por su derecho a votar y a ser elegidas. Fundadora de dos publicaciones, Le Papillon y La Revue Cosmopolite, Audouard recibió el apelativo de bas-bleu, adjetivo con el cual se denominaba peyorativamente a las mujeres que tenían ambiciones intelectuales. Como viajera, realizó una travesía por América del Norte y Rusia; también recorrió Egipto y Turquía.
} 
En las descripciones que Audouard hace de los harenes, hay una serie de elementos que son recurrentes en los textos del resto de pasajeras a Oriente. Se trata de la dejadez física y moral de las mujeres que los habitan, la falta de instrucción que muestran, de los celos surgidos entre ellas, de la atmósfera pesada, casi angustiosa para las europeas y, cuando se trata de harenes que pertenecen a las clases pudientes, la suciedad impera.

Como hemos apuntado, la catalana Aurora Bertrana se suma igualmente a la corriente que toma el harén como motivo de inspiración literaria. La periodista fue invitada a compartir una comida en casa de un ministro musulmán; esta visita le sirvió para observar los contrastes existentes entre los hombre ricos y cultos y aquellos otros que formaban parte "del otro Marruecos, feroz, guerrero, fanático y piojoso" (2000 [1936]: 50); pero también le sirvió para curiosear en el harén de un hombre importante. La primera evidencia que tubo de la presencia de mujeres en aquel lugar la describe así:

\footnotetext{
Fumábamos y bebíamos apoyados en cojines. Yo conversaba con el estudiante turco sobre política femenina, cuando mis ojos distraídos se elevaron hacia las altas ventanas enrejadas que se abrían sobre el patio central. En cada abertura había un montón de mujeres, bien hacinadas. ¡En medio del envoltorio de sus túnicas blancas, los ojos negros bordeados de cahol, contemplaban curiosos y celosos a aquella extranjera vestida con tela de hilo, luciendo piernas y brazos, fumando, charlando, discutiendo con los hombres! (Bertrana 2000 [1936]: 53)
}

Resulta evidente que Aurora Bertrana, suponiendo los celos de las musulmanas hacia ella misma como extranjera, proyecta en las mujeres del país que visita la mentalidad occidental; atendiendo a la condición sexual que las une, busca, como en un espejo, la propia imagen, pero el espejo le devuelve una visión en la que no se reconoce. Demuestra, de esta manera, un sentimiento de superioridad propiciado por su origen cultural, sentimiento que no le permite situarse de forma objetiva en la posición de la otra ni preguntarse de qué manera viven las mujeres orientales la intrusión, casi la profanación, del harén por parte de una mujer que no acata sus costumbres. La periodista catalana, más que la sensualidad de aquellas miradas, prefiere destacar el hecho de que, a su entender, destilaban una cierta envidia al contemplar la libertad de que gozaba la extranjera: libertad por lo que se refiere a la indumentaria y, también, una libertad que le permitía gozar e intervenir en la conversación de los hombres.

Fuere cual fuere el pensamiento de las mujeres del harén, el anfitrión ofreció a la periodista catalana la posibilidad de visitarlo y la escritora, naturalmente, aceptó encantada. Detengámonos un momento en la descripción de esta experiencia y observemos una vez más la repetición de los tópicos orientalistas:

\footnotetext{
Dejamos el patio de mármoles y mosaicos, que tenía una fuente de mayólica. Entramos a una escalera estrecha. Salimos a una galería alta que se iluminaba por una claraboya de cristales de colores. Nos paramos enfrente de una puertecilla dorada, la del lugar sagrado. Él la empujó. Juntas en el suelo, en colchones satinados, las mujeres bebían té y comían dulces. [...] Había algunas jóvenes, otras eran viejas, unas feas y otras guapas, blancas y negras, libres y esclavas. Formaban un grupo llamativo y atrayente. Lucían ricos caftanes de satén, túnicas de muselina, cinturones i babuchas bordados. Sus cabezas y brazos aparecían emperifollados con oro. (Bertrana 2000 [1936]: 53-54)
}

Habitualmente, las viajeras plasman la dificultad que supone penetrar en el harén a causa del laberinto de escaleras y pasadizos que obstaculizan su acceso; esta misma inaccesibilidad refuerza el deseo del occidental de penetrar al recinto de las mujeres con la finalidad de confirmar los estereotipos que guarda en su imaginario. Sin duda, muchas autoras reflejan 
un ambiente sensual donde las mujeres son tratadas como objetos de lujo, aunque en contrapartida permanecen faltas de libertad de movimiento, de libertad de actuación y, por tanto, la pereza se apodera de su cuerpo e incluso de su espíritu.

En la descripción de Aurora Bertrana aparecen el patio de mármol, la fuente, los colchones satinados, el té, los bordados, las joyas, toda una serie de elementos que se repiten en el discurso orientalista y que reproducen y conforman el imaginario colectivo. Pero es evidente que este ambiente de lujo no puede adscribirse más que a una clase social alta, aquella a la cual pertenecen las mujeres de un ministro, por ejemplo. Teniendo en cuenta que el texto de Bertrana se escribió durante el año 1935, parece evidente que, por lo que respecta al tema del harén como espacio simbólico, la autora busca complacer al lector, ofrecerle aquella dosis de sensualidad que anuncia el título de su libro y que, por otra parte, caracteriza tradicionalmente una lectura ambientada en el norte del continente africano.

Hablamos de un intento de complacencia de la escritora catalana hacia el lector teniendo en cuenta que los harenes imperiales se dieron por desaparecidos a partir del 1909. El harén con que se encontró Aurora Bertrana tenía que ser, por tanto, un harén doméstico, bastante alejado del sensualismo que había causado impacto en la imaginación occidental. No obstante, Bertrana adopta aquel imaginario del harén que había sido convenido y consensuado en su propio mundo. Este hecho, resulta evidente, acerca el texto de la autora al concepto de literaturización, al tiempo que aleja los hechos de la veracidad que la cronista defiende en la justificación que da paso a la obra.

Sea como fuere, la mentalidad de las mujeres orientales vinculadas a un harén llama la atención a las viajeras occidentales. Bajo su punto de vista, parecen perezosas, poco curiosas y poco ávidas de conocimientos, cosa que las induce a continuar en la indigencia cultural a la que el harén las condena de antemano.

Este pensamiento está bastante generalizado entre las viajeras. Barbara Hodgson (2005: 115-116) propone otros nombres que ejemplifican esta situación: Jane Digby se queja de la sociedad de la mujer oriental y de la simplicidad de sus conversaciones. Ida von Hahn-Hahn habla de mujeres intelectualmente limitadas y alude a ellas con el sustantivo hembras y no con el de mujeres. Olympe Audouard se refiere igualmente a hembras. Harriet Martineau, después de una experiencia en unos baños turcos, afirma de las mujeres que los frecuentaban que no se las podía considerar como seres humanos. También la catalana Aurora Bertrana utiliza la palabra hembras para señalar a las mujeres que habitan un harén: "Él, con toda su importancia, está satisfecho de poder demostrar a la periodista europea que un bajá marroquí tiene suficiente prestigio y suficiente dinero para lucir casa y hembras de primer orden" (Bertrana 2000 [1936]: 71).

Los libros de viaje de Audouard ejemplifican con creces el grado de animalización que, a su parecer, adquirían las mujeres que permanecían encerradas en el harén. Se trata de una animalización causada por la falta de educación y que se materializa en un comportamiento sexual interesado, incluso promiscuo:

Hay, es verdad, tanto aquí como en Estambul, algunas mujeres distinguidas, que tienen una cierta educación, pero son escasas, y en ese caso son hijas de beis, de bajás, a quienes se ha hecho dar alguna instrucción.

Por lo que se refiere a las otras, son criaturas que tienen solamente el instinto bestial. Viven para comer, dormir bien, vestirse ricamente, en el amor no ven más que el amor físico, el de la bestia... Cualquier hombre para ellas es un hombre, y los beis y los bajás de aquí tienen a menudo a sus propios sirvientes por rivales, incluso antes que a los europeos o a otros señores del país. Las mujeres prefieren 
pues a sus sirvientes, esto les ofrece menos peligro, y ellos están a su alcance con mayor facilidad. (Audouard 1866: 425)

Así pues, observamos que, en un número importante de ocasiones, atendiendo a la mirada de la mujer occidental, la vida en el harén se considera causante de situaciones negativas hacia la mujer. La falta de instrucción asociada al escaso desarrollo intelectual del género femenino es una de las más relevantes, la que la sentencia a vivir en un estado cercano a la animalización.

\subsection{Del olor como tópico recurrente a la degradación moral o a la obediencia}

Otro de los tópicos recurrentes en el momento de describir un harén es el olor peculiar que desprenden, la poca ventilación, el aire enrarecido que se respira, ocasionado en buena medida por el encierro físico de las mujeres. Cristina Trivulzio di Belgiojoso incide en este aspecto:

Lo que falta por completo en estos apartamentos, es el aire, pero estas mujeres están lejos de quejarse de ello. De naturaleza prudente y no teniendo la posibilidad de calentarse mediante el ejercicio, permanecen horas enteras en cuclillas delante del fuego, y no comprenden que esto algunas veces ahoga. (Belgiojoso 1858: 18)

También resulta habitual que, al salir del harén y respirar el aire libre, la visitante valore la propia posición como mujer occidental. La misma Aurora Bertrana se refiere a la falta de aire en los harenes, al tiempo que asocia el Occidente al aire puro como símbolo de libertad:

Me sentía medio mareada en aquel ambiente recluido, donde se mezcla el perfume embriagador de las mujeres con el aroma sano de las hierbas. - Id con Dios...

Media hora después me encontraba en la calle, respirando el aire puro de las montañas cercanas, contemplando la huerta verde y amarilla que se extiende hasta el mar y siguiendo enternecida una nube blanca que volaba hacia Occidente sobre el Mediterráneo amigo. (Bertrana 2000 [1936]: 54)

Son diversas las ocasiones en que la autora catalana hace referencia a la necesidad de oxigenarse después de haber visitado un harén, ya fuera éste de condición social elevada o más humilde. La falta de oxígeno, el aire viciado, se asocia directamente a la falta de libertad de las mujeres, tanto por lo que se refiere a los harenes turcos descritos por Belgiojoso como a aquellos que encuentra Aurora Bertrana unas décadas más tarde. Además, esta especie de envilecimiento físico se pone en relación directa con la degradación moral que experimentan las mujeres. Las viajeras observan en las orientales una ausencia de valores morales estrechamente ligada a la vida recluida del harén. La misma Belgiojoso conecta los diferentes tipos de degradación - física, intelectual, sexual y moral一, y afirma: "La expresión de su rostro es a la vez la estupidez, una sensualidad grosera, la hipocresía y la dureza. No hay el mínimo rastro de principios morales o de creencias religiosas" (Belgiojoso 1858: 101). Esta situación afecta directamente al sentimiento maternal de las mujeres: "Sus hijos las ocupan y las molestan a la vez: los cuidan como vehículo que les sirve para alcanzar el favor de sus esposos, pero cualquier pensamiento de deber maternal les resulta extraño" (Belgiojoso 1858: 101). La ausencia de una estructura familiar en que la madre ejerza el papel central, explica la degeneración de la mujer, que pierde el sentimiento maternal que debería serle inherente. 
Ahora bien, en los harenes que recrea Aurora Bertrana, en cambio, no se habla de forma explícita de una ausencia de principios morales o religiosos imputable a las mujeres. La obediencia y el silencio son los ejes vertebradores de la conducta de las orientales que, simplemente, se limitan a obedecer las indicaciones de su dueño. Este silencio se convierte en la metáfora de la obediencia al hombre, hasta el punto que auto anula con resignación los deseos y las opiniones del género femenino. En este sentido, el relato de El Marroc sensual i fanàtic no pretende ofrecer simplemente una visión estereotipada de la alteridad por parte de Aurora Bertrana. Más allá de esto, pretende indagar en el estado anímico de las mujeres que se enfrentan a situaciones de esta índole.

\subsection{Ellas también son humanas. Ellos también son víctimas}

Si dirigimos nuevamente la mirada a las viajeras europeas, podremos observar que la prosa de viajes de Cristina Trivulzio di Belgiojoso, aparte de recrear en algunos pasajes las escenas más prototípicas de la vida en los harenes, ofrece una visión muy humana de las mujeres, que se aleja sustancialmente de las envidias que con asiduidad relatan las viajeras occidentales. Entre las mujeres que habitan el harén de un bajá puede surgir un sentimiento de hermandad propiciado no justamente por el hecho de compartir el mismo hombre, sino a causa de participar de unas mismas circunstancias de vida. Belgiojoso caracteriza de esta manera a una de las mujeres musulmanas que conoció:

\footnotetext{
Pero lo que me llegó al corazón más que todos los cumplidos y todas las caricias que ella me prodigó, fueron los cuidados que me pareció que daba de todo corazón a la segunda esposa de su marido, afectada por una parálisis casi general y por una enfermedad escrofulosa de las más lamentables —Esta desgraciada se hacía llevar a casa de su compañera que, cuando la veía entrar, solamente se ocupaba de ella [...] En la mirada de esta orgullosa y robusta beldad se podía hallar todavía, ciertamente escondida bajo la viva imagen del sufrimiento y de la muerte, quién había sido y quién podía ser todavía su rival (pues ¿quién puede medir el alcance de las fantasías de un marido turco?) había allí alguna cosa noble y grande, como yo no estaba demasiado acostumbrada a encontrar ni en el corazón, ni en el rostro de los habitantes de los harenes. (Belgiojoso 1858: 405-406)
}

Pero el caso que relata Belgiojoso no se adapta a la clasificación que Olympe Audouard propone cuando se refiere a las musulmanas que habitan un harén. Audouard se atreve a distribuir a las mujeres orientales en tres grupos: el de aquellas que viven felices en el harén, aquel otro conformado por las mujeres que se resignan a hacerlo y el de aquellas otras que muestran el disgusto que les causa compartir el amor del marido con otras mujeres:

\footnotetext{
Las mujeres turcas pueden clasificarse en tres categorías.

La primera, que es bastante numerosa, se compone de aquellas que se toman con mucha paciencia su vida en un entorno poligámico [...]. Esta categoría me inspira un desagrado profundo. A mi parecer, una vida semejante es una vida de prostitución, y yo considero a esos seres como hembras y no como mujeres.

La segunda categoría está formada por aquellas que soportan con paciencia y resignación la poligamia, pero sufren con ello y conservan su dignidad de mujer. [...] Para esta categoría, uno no puede más que sentir una estima y una simpatía profundas.

La tercera categoría es aquella de las mujeres celosas; aquellas que chillan, lloran, lo rompen todo, y algunas veces envenenan o apuñalan a su marido o a su rival. (Audouard 1866: 94-98)
}

Audouard reconoce sentir especial simpatía hacia aquellas mujeres que viven con conformidad la vida que les es impuesta en el harén. Justamente es esta segunda categoría de mujeres, según la clasificación de Audouard, la que da cuerpo al relato de Bertrana: la 
sumisión y la abnegación son los rasgos que las caracterizan. Pero, a pesar de esta situación claramente desfavorable para las mujeres, Audouard opina que la falta de una estructura familiar que esté enraizada en la moral cristiana impide también al hombre conseguir la felicidad; en este sentido, el género masculino se convierte, igual que la mujer, en una víctima del harén como institución que regula el núcleo familiar:

\footnotetext{
Vamos, queridos lectores, no envidien demasiado la suerte de estos ricos pachás que tienen hasta cuatro mujeres legítimas, y un número ilimitado de odaliscas; con este lujo de mujeres o más bien a causa de este lujo de mujeres, es raro que tengan el amor de una sola, y ellos, ;itienen dificultades para calmar las tormentas de su interior! O más bien, ellos no tienen interior, ignoran la dicha, la tranquilidad del hogar doméstico... son más dignos de lástima que de envidia. (Audouard 1866b: 93)
}

Olympe Audouard todavía más lejos cuando afirma que aquellos hombres que se acomodan a la voluptuosidad de la vida en el harén pierden toda la energía e, incluso, la inteligencia, de manera que acaban envileciéndose. Contrariamente, la autora catalana en ningún momento se acerca a esta visión del hombre como ser perjudicado por las costumbres musulmanas relacionadas con la vida familiar. A pesar de ello, Bertrana no olvida consignar en sus escritos el haditz que autoriza al hombre a poseer cuatro mujeres legítimas siempre que dé a cada una la parte del amor que le corresponde. El musulmán, pues, contrae nuevas obligaciones a medida que amplía la familia. Se trata de obligaciones materiales, ya que debe sustentar económicamente a la mujer y a la descendencia futura, pero, especialmente, hace referencia a obligaciones de tipo moral cuando alude al amor compartido al cual la nueva esposa tiene derecho. Para Aurora Bertrana, los dueños de los harenes muestran su carácter condescendiente cuando permiten la visita a la periodista; aparecen magnificentes y orgullos de las mujeres que poseen, a pesar de que su rostro refleja el cansancio ocasionado por las responsabilidades: "El bajá contempla satisfecho a sus mujeres, cubiertas de sedas, de bordados y de joyas. [...] Los ojos cansados del bajá siguen la operación [del ritual del te], notablemente satisfechos" (Bertrana 2000 [1936]: 73).

Bertrana no busca profundizar en la psicología masculina por lo que se refiere al tema del harén; se conforma con ofrecer una visión estereotipada amparada en la habitual reserva musulmana. En El Marroc sensual i fanàtic, el hombre se limita a cumplir la misión que la sociedad oriental establece: la del dueño, anfitrión, suministrador del bienestar material del hogar y con la obligación de tener descendencia a cualquier precio. Por este motivo, también puede padecer las consecuencias negativas ocasionadas por la presión de una sociedad anclada en la tradición y que se niega a evolucionar. Con todo, a él le toca la parte de sujeto activo; a ella, en cambio, le corresponde representar el papel de objeto que se puede mostrar con orgullo o repudiar.

\subsection{El paso de objeto a sujeto: la religión y la cultura como obstáculos}

Para Monicat, el paso de objeto a sujeto sólo puede llevarse a cabo por medio de la instrucción: “¿Cómo dejar de ser objeto? Siendo sujeto pensante. En el núcleo de este debate se encuentra todavía la cuestión de la educación: es lo que libertará a la mujer" (Monicat 1996: 109). En este mismo sentido se han manifestado muchas viajeras, que ven en la instrucción de la mujer la herramienta clave para que pueda salir del abatimiento en que el harén la tiene sumida. Veamos algunos ejemplos: 
La mujer oriental está muy persuadida de su inferioridad frente al hombre (ciertamente por desgracia). Se la educa en esta creencia; se ha hecho de todo para impedir que su inteligencia se desarrolle a través de la educación a fin de que ella conserve la idea de su inferioridad. Además, ella considera generalmente a su marido como a un maestro, un ser que se encuentra por encima de ella, no como a un igual, su amigo, su esposo (Audouard 1866: 188).

También Belgiojoso expresa un sentimiento similar en estos términos:

Y si él trata a la suya [ a su mujer] poco más o menos como a un ser privado de razón, es porque ella no hace nada para elevarse a una condición mejor [...] sí, son turcas en el sentido que ustedes dan a esta palabra, es decir, criaturas sin razón y degradadas; pero ¿quién las ha convertido en eso? ¿Y por qué el nombre que se da a sus compañeras se ha convertido en sinónimo de bajeza e incultura aplicadas a las mujeres? (Belgiojoso 1858: 110-111)

La visita de Ida Hahn-Hahn a un harén de Damasco no provoca en ella impresiones diferentes a las del resto de viajeras occidentales. Hahn-Hahn califica también a las musulmanas como sucias, negligentes y desagradables, al tiempo que culpabiliza al harén de este envilecimiento. Des de su punto de vista, el harén humilla a la mujer ya que la trata como si fuera un animal. A pesar de ello, este sentimiento que aproxima a la autora a la reivindicación de los derechos inalienables de las mujeres, queda de lado y, en su texto, la viajera alemana no desarrolla ninguna idea de fraternidad hacia sus congéneres musulmanas; las diferencias culturales resultan demasiado abismales, de tal manera que no es posible la comunicación entre ellas. Con todo, cabe subrayar que para Hahn-Hahn el principal obstáculo para el entendimiento entre civilizaciones es de tipo religioso: la poligamia se convierte en la materialización de un muro infranqueable y altamente condenable que separa a los musulmanes de los cristianos (Moussa 1995: 188).

De forma similar, en una conferencia pronunciada en el Ateneu Barcelonés a raíz de su estancia en Marruecos, Aurora Bertrana habla así de las mujeres musulmanas:

He creído descubrir que las mujeres musulmanas no tienen alma. Es decir, que carecen en absoluto de vibraciones espirituales. Las tradiciones, los principios alcoránicos, la superioridad social masculina, todo conspira contra el desarrollo del espíritu femenino musulmán [...].

Le pregunté también si la mujer aprendía, como él, árabe y latín. Se encogió de hombros, muy desdeñoso, qué quieres que haga: las mujeres no deben hacer más que trabajos manuales. Efectivamente, un viejo proverbio árabe dice: "enseña a tus hijas a hilar y no a leer".

La autora catalana acusa a las mujeres musulmanas de inconscientes e irresponsables i afirma: "Parece que ni Alá ni el Sultán, ni los cadis ni los maridos consideran a la mujer como ser humano, consciente y dotada de alma. Más bien parece un verdadero instrumento de lujo, de gozo, de vanidad o de procreación"11. La cultura, la religión, e incluso el talante de las mismas mujeres, todo parece estar en contra de propiciar el paso que debería llevarlas de la cosificación a ser sujetos pensantes, más allá del gozo y del dolor experimentado en el interior de un harén: la instrucción.

\footnotetext{
${ }^{11}$ Son palabras pronunciadas durante la conferencia de Aurora Bertrana que lleva por título "L'amor al viatge".
} 


\section{Algunas conclusiones}

En el siglo XVIII, Lady Mary Wortley Montagu fue considerada la primera mujer europea en proporcionar la descripción del interior de un harén. Erigido en símbolo de una cultura, el harén ha despertado siempre la curiosidad de los occidentales; una curiosidad promovida por la difusión de los estereotipos orientalistas que definían una alteridad que no siempre se acercaba a la realidad que encontraban los viajeros: el lujo, la voluptuosidad y el desenfreno sexual de los cuentos de Las mil y una noches eran a menudo sustituidos por realidades más prosaicas.

Las mujeres europeas, como los hombres, no pudieron sustraerse al deseo de constatar por ellas mismas hasta qué punto la realidad y la ficción se mezclaban en esas historias. Su testimonio, materializado en la escritura de libros de viajes, es valioso en tanto que complementa una visión, hasta ahora parcial, de la alteridad. En sus escritos, viajeras como Cristina Trivulzio, Olympe Audouard, Carla Serena, Ida von Hahn-Hahn o Aurora Bertrana defienden ser las auténticas conocedoras de la vida en los harenes, en detrimento, confirmación o complemento, de la verdad presentada por los viajeros varones. Los testimonios mostrados en este trabajo pertenecen a viajeras de nacionalidades europeas diversas y sus escritos, así como las fechas en que viajaron a países adscritos a la cultura oriental, oscilan entre los años cuarenta del siglo XIX i los treinta del XX. No obstante, esto no impide que en todas ellas se aprecien algunas constantes temáticas - como la curiosidad inspirada por la vida en el interior de un harén-y de opinión.

En general, coinciden en la sensación de desencanto al topar con una sociedad menos exuberante de la que esperaban: el misterio del harén suele esfumarse cuando las viajeras observan una institución familiar aceptada cultural y socialmente, incluso por las mismas mujeres, que las mantiene bajo un índice de analfabetización y de apatía realmente cuestionable. La belleza exótica de las mujeres también resulta un tópico a tener en cuenta: el encierro a que se ven sometidas las convierte, a menudo, en mujeres obesas a las que les cuesta caminar. La atmósfera poco aireada de los harenes se convierte, para unas, en símbolo de la degradación moral que padecen, en tanto que, para otras, las reafirma en su orgullo de mujeres occidentales. En cualquier caso, la religión es el elemento clave que aleja y contrapone ambas culturas, que impide una comunicación fluida entre ellas y que impone el silencio y la obediencia entre las mujeres musulmanas.

Por lo que se refiere a la autora catalana, su libro de viajes, El Marroc sensual y fanàtic, se adscribe a la perfección a la corriente literaria que las viajeras europeas habían iniciado décadas atrás. El Oriente al que nos acerca se ciñe, por lo que respecta a los harenes y a las mujeres que los ocupan, a los estereotipos habituales. Bertrana presenta, en algunos casos, mujeres cubiertas de sedas, bordados y joyas, amables y silenciosas, que la obsequian con cumplidos. Las únicas curiosidades que manifiestan las musulmanas que visita se refieren al carmín de labios o al esmalte de uñas de la occidental. La sensualidad está presente en diversos episodios de su narración, de hecho, se incorpora desde el mismo título de su crónica de viaje.

Con todo, la periodista imagina los dramas de aquellos hogares, habitados por mujeres que llevan vidas "escondidas, sensuales y turbulentas" (Bertrana 2000 [1936]: 74). Las orientales no manifiestan ninguna opinión remarcable hacia la occidental, así como tampoco no osan revelar los propios sentimientos. En este sentido, Aurora Bertrana tiene que conformarse con permanecer en la ignorancia a que el silencio de las mujeres musulmanas la condena. Su visión de los harenes a los que es invitada es la de una outsider. La misma 
autora reconoce que sale de ellos tan ignorante como entró. Sin embargo, la brevedad de las visitas de la cronista y la impenetrabilidad de las mujeres que los habitan, no consiguen esconder la complejidad de las relaciones humanas que tienen lugar en aquellos lugares cerrados, prohibidos a las miradas indiscretas que provienen de la cultura occidental.

\section{Bibliografía}

Audouard, O. (1866a): Les mystères du Sérail et des Harems Turcs. Paris: E. Dentu, Éditeur.

Audouard, O. (1866b): Les Mystères de l'Égypte Dévoilés. Paris: E. Dentu, Éditeur.

Belgiojoso, C. (di) (1855): "La vie intime et la vie nomade en Orient, scènes et souvenirs de voyage", in Revue des deux mondes, I, 1er février 1855, tome IX: 466-501; 2, 1er mars 1855, tome IX: 1020-1050; 3, 1er avril 1855, tome X: $60-90 ; 4$, 1er setembre 1855 , tome II: 1201-1233.

Belgiojoso, C. (1858): Asie Mineure et Syrie, souvenirs de voyages. Paris: M. Lévy.

BERTRANA, A. (1936): "L'amor al viatge", conferència mecanoscrita conservada en el Fons Bertrana de la Universitat de Girona.

Bertrana, A. (1973): Memòries fins al 1935. Barcelona: Editorial Pòrtic.

BertranA, A. (2000): El Marroc sensual i fanàtic. Barcelona: Columna.

CHARDin, J. (1686): Voyage de Monsieur le Chevalier Chardin en Perse et Autres Lieux de l'Orient, 2 vols., Amsterdam.

Hodgson, B. (2005): Rêve d'Orient. Les Occidentales et les voyages en Orient. XVIIIe début du XXe siècle. Paris: Éditions du Seuil.

KABBANI, R. (1986): Europe's Myths of Orient. Devise and Rule. Great Britain: Macmillan.

MonicAT, B. (1996): Itinéraires de l'écriture au féminin. Voyagueses du 19e siècle. Amsterdam: Editions Rodopi.

Moussa, S. (1995): La relation orientale. Enquête sur la communication dans les récits de voyage en Orient (1811-1861). Paris: Klincksieck.

NoGUÉ I FONT, J. et al. (1996): “Orientalisme, colonialisme i gènere. El Marroc sensual i fanàtic d'Aurora Bertrana”, Documents d'Anàlisi Geogràfica 29: 87-107.

RatTAZzI, M. (1897): Lettres d'une voyageuse: Vienne, Budapest, Constantinople. Paris: Felix Alcan.

SERENA, C. (1881): Mon voyage: Souvennirs personnels. De la Baltique à la mer Caspienne. Une Européenne en Perse, 2 vol. Paris: Maurice Dreyfous. 